G180(P) SUDDEN UNEXPECTED DEATH IN INFANCY AND CHILDHOOD - SIMULATION TRAINING TO IMPROVE CONFIDENCE AND UNDERSTANDING OF THE SUDIC INVESTIGATION

A Belfitt, AD Holt, A Copeman. Paediatric Department, New Cross Hospital, Wolverhampton, UK

10.1136/archdischild-2018-rcpch.175

Introduction Paediatricians play a vital role in managing the multi-agency investigative process following a sudden unexpected death in infancy or childhood (SUDIC). Inadequate SUDIC investigation has devastating consequences for families and professionals.

The low incidence of SUDIC and shortened training time result in reduced exposure. The Kennedy Report highlighted the need for improvement of training. Despite these recommendations a lack of experience and awareness of the multiprofessional roles exists amongst senior trainees.

Simulation-based education has been used effectively to bridge the gap between knowledge and clinical experience. We developed a one day course for senior paediatric trainees and consultants using high fidelity simulation and experiential learning.

Methods Key events of a SUDIC case and investigation were simulated including:

- Resuscitation

- Breaking bad news

- Post-mortem examination and investigations

- Death scene examination

- Rapid response meeting

- Report writing

- Parent experiences

Content and scenarios were mapped to the Postgraduate $\mathrm{RCPCH}$ Curriculum for General Paediatrics and Community Child Health, and delivered by SUDIC specialists within paediatrics and police.

Outcomes assessed included qualitative pre- and post-course confidence and self-reported skills performing key aspects of SUDIC management.

Results Seven SUDIC simulation courses have been delivered to date (2016-2017), with 8-15 candidates in each. Significant improvement was seen between pre- and post-course Likert scores for confidence and skills in all key aspects; including confidence explaining the process to parents (increased from $14.3 \%$ to $90.9 \%$ ) and practical skills e.g. performing skin biopsy (from $17.9 \%$ to $87.9 \%$ ). Free text feedback comments were overwhelmingly positive - referencing much improved understanding of the investigative process.

Conclusion Simulation training improved confidence and perceived ability to manage key aspects of SUDIC - an area where self-reported confidence and skills are low due to little clinical exposure. This may ultimately improve the quality of SUDIC investigations and experiences for families.

This course is funded for all trainees within our deanery. It has the potential to be delivered nationally and could be adopted for multi-professional SUDIC training for health, social care and police.

\section{G181(P) EXPLORING COMPLEMENTARY FEEDING PRACTICES (CFP), CONCERNS AND DRIVERS IN THE BRITISH BANGLADESHI POPULATION, TO OPTIMISE INFANT NUTRITION AND LIFELONG WELLBEING}

LM Benton, T Smith, M Lakhanpaul. Population, Policy and Practice, Great Ormond Street Institute of Child Health, University College London, London, UK

10.1136/archdischild-2018-rcpch.176

Aims To explore complementary feeding practices (CFP), concerns and drivers in Bangladeshi communities to inform the adaptation of a female volunteer-led participatory learning and action cycle based intervention to optimise infant (624 month) nutrition and prevent long term conditions such as obesity and diabetes.

Methods The NEON (Nurture Early for Optimal Nutrition) study utilised collaborative participatory approaches, working with trained community researchers. A snowballing technique was used to achieve a purposive sample of Bangladeshi mothers, fathers and pregnant women living in the $\mathrm{UK}>3$ or $<3$ years and grandparents, community members, key informants and health professionals with experience or professional interests in CFP in the UK health context. Qualitative topic guides were informed by the literature and guided by a socio-ecological framework. Semi-structured interviews (45) and focus group discussions (12) were conducted in homes and community spaces by a trained Bangladeshi community facilitator and the researcher. Data were analysed using Framework methodology in NVivo.

Results Families reported diverse methods use to feed infants aged 6-24 months, including: cup, beaker, spoon, syringe and 'modified bottle', and styles of feeding, including: distraction feeding, 'force' feeding, messy eating and responsive feeding. Common practices included mixed breast and bottle-feeding, or switching to bottle to facilitate early weaning. Some preferred formula that is thickened or advertised as for hungry babies and the early introduction of cow's milk. Hand feeding was common as a tradition, for ease and a show of love. Respondents described a range of concerns and worries related to complementary feeding: early weaning, filling the belly, fussy eaters, understanding good growth and development, health in childhood (including obesity and dental caries), health in adulthood (including chronic diseases), overfeeding, safety and unhealthy food preparation. Societal views that 'a chubby baby is a heathy baby' were linked with parental concerns about 'filling the belly' and professional concerns for 'overfeeding'.

Conclusion Long-term health can be influenced by optimal infant nutrition. Interventions need to recognise the socio-cultural drivers of CFP practices to develop targeted and acceptable programmes.

\section{G182(P) USE OF AN ECLECTIC APPROACH IN AUTISM SPECTRUM DISORDER; A DEVELOPING COUNTRY PERSPECTIVE}

S Maqbool, W Zahra, E Ullah, A Farid. Department of Developmental and Behavioural Paediatrics, The Children's Hospital and The Institute of Child Health, Lahore, Pakistan

10.1136/archdischild-2018-rcpch.177 